\title{
A Frame of Reference at Sea
}

\section{from Lieutenant-Commander N. L. Fendig, U.s.c.G.}

DESPITE increasing use of radar, marine collisions have continued to occur in significant number. The principal reason advanced for this development has been the 'human element' and many new electronic innovations have been suggested or built to minimize this factor. This note is written not for the purpose of providing an absolute answer to the problem, but rather to suggest there may be another angle from which it may be approached.

When an interscholastic or professional sport results in too many injuries; the players are not blamed. The authorities of the game, however, take a long, hard look at the rules. That is what is suggested-a long, hard look at the rules. The nautical Rules of the Road are arbitrary rules which have been formally. adopted and followed by the various maritime nations for slightly less than a century, though it may be presumed that they were based on previously existing customs and traditions.

The essence of the Rules lies in the steering and sailing articles. The steering and sailing rules are based upon a subjective frame of reference for the watch officer conning each vessel. His action must be based upon the bearing of another vessel relative to the heading of his own vessel, as well as his appraisal of the heading of the other vessel. Drawn up in the middle of the nineteenth century, the Rules of the Road adopted a frame of reference which was familiar to every mariner, the heading of his own vessel. Considering the state of the technology of navigation in that period, it is doubtful that a more widely known objective criterion for action would have been feasible at the time.

The meaning of the preceding paragraph will be clearer if, in place of the present steering and sailing rules, we postulate another basic rule to govern the responsibility for avoiding collision when vessels encounter each other. Because it is hypothesized only for the purpose of this discussion, it is oversimplified.

'When a vessel encounters another vessel in such manner that collision may result, that vessel whose position is to the east or south of the other vessel shall take all necessary action to avoid collision, and if unable to take such necessary. action, shall immediately stop and blow a series of short blasts at frequent intervals to indicate her inability'.

Our frame of reference has now become objective, being based on the currently well known factors of geography and direction in place of heading. Should collision occur, fault may be readily inferred from the point of departure and the point of destination of the colliding vessels in most instances.

The present steering and sailing rules provide only for those cases in which vessels are visible to each other. The mental conditioning inherent in these rules, however, greatly affects the actions of vessels which only hear each other's fog signals or detect each other by means of radar or other electronic device.

Our postulated rule need not suffer from such an ambiguity. No stipulation needs to be made concerning visibility, and there need be no doubt as to who is responsible for taking suitable action. There is no necessity for radiotelephonic communication between vessels such as that which has been proposed. Vessels not fitted with radar, or incapable of taking the necessary evasive action for any reason have the option of stopping and blowing an appropriate signal. The only instrument required to determine responsibility is a compass. You are obliged 
to avoid the other vessel if her position is north or west of the position.of your vessel.

Heading as a basis for determining the responsibility of who should take avoiding action suffers from a number of detracting factors in addition to the fact that it is not always obvious to another vessel. A lightly burdened vessel in a gale of wind is seldom heading in the direction in which she is going. The same situation, in some degree, results from the effects of currents. The steaming lights, in many instances, provide more of an expression of the intended than the actual course. Our postulated rule change, it should be noted, makes no reference to changes in the steaming lights required to be carried; only the manner of placing the burden of responsibility is altered.

Progress in nearly every field has been marked by the substitution of objective standards for personalized reactions as a basis for action. The international metre and gramme provide a common measure for nations to use in reckoning their commercial dealings. Can true direction provide a common standard for maritime regulations to prevent collisions?

\section{Clarifying the Rules of the Road at Sea from Commander P. Clissold, R.N.R.}

IT may not be humanly possible to draw up a code of rules for international use which are completely comprehensive and clear in every particular. The Rules for Preventing Collisions at Sea are not, and it would be useful to know the accepted interpretation of doubtful points. Criticism of the Rules is not here intended, and all references to the impact of radar upon their interpretation is omitted, as this question is now being studied by a Working Party. Suggested correct interpretations are added in brackets.

Rule 3. A vessel towing another vessel, and controlling the towed vessel only with difficulty (e.g. one ship towing another and only capable of altering course or speed gradually): should the two red lights (Rule 4 for vessels not under command) be carried in addition to the towing lights? (Yes.)

Rule 8. A power-driven pilot vessel when engaged on her station on pilotage duty and not at anchor: should she carry a stern light? (The Rule implies that she should not, but it is believed that some pilot vessels do. Since she carries side lights common-sense suggests that she should carry a stern light too.)

Rule $9(h)$. Vessel when fishing fast by her gear to a rock, \&c. : should she haul down the 3 white lights in a triangle? (Rule implies that she does, but implies that by day the cone is left up. Common-sense suggests that she would leave it up.)

Rule I I. A vessel at anchor by the stern (e.g. a trawler with her trawl fast to the bottom): should the anchor ball be hoisted aft and not forward? (Yes.)

Rule i $5(b)(i)$. If the whistle of a power-driven vessel breaks down, what signal should she make? (D upon the foghorn, as 'being unable to manœuvre as required by these Rules'.)

Rule I 5 (b) (ix). Should a vessel engaged in fishing at anchor make the fogsignal for a vessel fishing or for a vessel at anchor? Similarly, a vessel working on a cable and at anchor.

Notices to Mariners No. 7 (7). Replenishment at sea. Should ships carry the usual steaming lights as well as not-under-command lights? (Side lights, but not masthead lights, should be shown.) 